\title{
Survey of cellular immune responses to human cytomegalovirus infection in the microenvironment of the uterine-placental interface
}

\author{
Takako Tabata $^{1} \cdot$ Matthew Petitt $^{1} \cdot$ June Fang-Hoover ${ }^{1} \cdot$ Lenore Pereira $^{1}[$
}

Received: 30 March 2019 / Accepted: 9 April 2019 / Published online: 7 May 2019

๑) Springer-Verlag GmbH Germany, part of Springer Nature 2019

\begin{abstract}
Congenital human cytomegalovirus (HCMV) infection is a leading cause of birth defects, yet there are no established treatments for preventing maternal-fetal transmission. During first trimester, HCMV replicates in basal decidua that functions as a reservoir for virus and source of transmission to the attached placenta and fetal hemiallograft but also contains immune cells, including natural killer cells, macrophages, and $\mathrm{T}$ cell subsets, that respond to pathogens, protecting the placenta and fetus. However, the specific cellular and cytokine responses to infection are unknown, nor are the immune correlates of protection that guide development of therapeutic strategies. Here we survey immune cell phenotypes in intact explants of basal decidua infected with a clinical pathogenic HCMV strain ex vivo and identify specific changes occurring in response to infection in the tissue environment. Using 4-color immunofluorescence microscopy, we found that at 3 days postinfection, virus replicates in decidual stromal cells and epithelial cells of endometrial glands. Infected cells and effector memory CD8+ T cells (TEM) in contact with them make IFN- $\gamma$. CD8+ TEM cells produce granulysin and cluster at sites of infection in decidua and the epithelium of endometrial glands. Quantification indicated expansion of two immune cell subtypes-CD8+ TEM cells and, to a lesser extent, iNKT cells. Approximately $20 \%$ of immune cells were found in pairs in both control and infected decidua, suggesting frequent cross-talk in the microenvironment of decidua. Our findings indicate a complex immune microenvironment in basal decidua and suggest CD8+ TEM cells play a role in early responses to decidual infection in seropositive women.
\end{abstract}

Keywords Cytomegalovirus $\cdot$ Placenta $\cdot$ Basal decidua $\cdot$ Natural killer $\cdot$ T cells $\cdot$ Interferon gamma

\section{Introduction}

Congenital human cytomegalovirus (HCMV) infection is a leading cause of permanent birth defects in the United States and worldwide, causing neurological defects ranging from mild hearing loss to deafness, severe cognitive deficits, microcephaly, and premature death. Most severe outcomes are associated with maternal infection in the first trimester of pregnancy [1-4]. Prior maternal exposure to HCMV reduces the risks of transmission and severe outcomes but does not

Edited by: Matthias J. Reddehase.

This article is part of the Special Issue on Immunological Imprinting during Chronic Viral Infection.

Lenore Pereira

lenore.pereira@ucsf.edu

1 Department of Cell and Tissue Biology, School of Dentistry, University of California San Francisco, San Francisco, CA 94143, USA eliminate them. Currently, there are no effective vaccines to prevent infection and no accepted treatments to prevent transmission to the fetus. Furthermore, immunohistological studies of placentas and serological analysis of maternal and cord blood from asymptomatic deliveries suggest that congenital infection (i.e., transmission) may be more common than previously thought, potentially causing unanticipated long-term sequelae in those that go undiagnosed.

The determinants and immune correlates of HCMV transmission are poorly understood. Analysis of placental and decidual biopsy specimens has revealed that HCMV replicates more often in the decidua than in the placenta, suggesting that the uterus functions as a reservoir for infection [5-7]. HCMV replicates consistently in epithelial cells of endometrial glands in basal decidua in first trimester and parietal decidua at term $[5,8,9,7]$. In reactivation, HCMV DNA was frequently detected along with the DNA of other viruses and pathogenic bacteria, suggesting the presence of other pathogens may trigger viral reactivation. In women with intermediate to high neutralizing titers, infection 
in decidua is suppressed, and the placenta spared [5, 8]. However, in a study of placentas from HCMV seropositive women, although neutralizing antibodies were detected, the placentas still contained viral DNA [10]. Moreover, placentas from seropositive women with pregnancies complicated by intrauterine growth restriction and preterm deliveries contain focal infection and fibrosis in parietal decidua and evidence of infection in epithelial cells of amniotic membranes, indicating virus transmission to the fetus [7, 11].

Comparison of HCMV and Zika virus showed similar replication patterns in epithelium of decidual glands and decidual stromal cells [12], but cytokines associated with immune cell activation and migration were upregulated in HCMV-infected decidua [13]. Nonetheless, both cellular and humoral responses reduce transplacental HCMV transmission. Analysis of immune cells in the circulation after primary infection showed early development of CD8 + and $\mathrm{CD} 4+\mathrm{T}$ cells and antibodies to the viral pentamer complex gH/gL-pUL128-131 in mothers who protect their babies from congenital infection [14, 15].

Given strong evidence that HCMV spreads from decidua to anchoring chorionic villi in early gestation, we carried out a preliminary survey of immune cells in basal decidua from first-trimester placentas infected ex vivo with a clinical pathogenic strain. Immunofluorescence analysis revealed changes indicative of inflammation and activation of cellular immune responses in the microenvironment of infected tissue, as described here.

\section{Materials and methods}

\section{Infection of decidua explants}

The Institutional Review Board of the University of California San Francisco approved this study. Basal decidua was isolated from placentas from elective terminations (Advanced Bioscience Resources). Basal decidua explants (approximately $2-3 \mathrm{~mm}$ ) were isolated and plated on Millicell-CM inserts $(0.4 \mu \mathrm{m}$ pore size, $30 \mathrm{~mm}$ (MilliporeSigma, Burlington, MA); 2-4 explants per insert) coated with Matrigel (B-D Biosciences, Franklin Lakes, NJ; diluted 1:1), and cultured in 96.5\% Dulbecco's Modified Eagle's Medium (DME) H-21 with 2.5\% fetal bovine serum (FBS). Twenty hours after attachment, explants were rinsed with fresh medium, infected with HCMV VR1814 strain $\left(3 \times 10^{6}\right.$ PFU) and maintained for 3 days before fixation and frozen embedding in optimal cutting temperature compound.

\section{Antibodies used in immunofluorescence}

Sections of control and infected decidua were immunostained for immunofluorescence using standard methods and mounted in VectaShield with DAPI (Vector Laboratories, Burlingame, CA). Antibodies used include monoclonal antibody CH443 targeting HCMV IE, produced in the Pereira laboratory, and the following antibodies obtained from commercial sources: mouse and rabbit antiCD3 mAbs (Abcam, Cambridge, United Kingdom), rabbit anti-CD4 mAb (Abcam, Cambridge, United Kingdom), rat anti-CD4 mAb (BioRad Laboratories, Hercules, CA), and mouse anti-CD8 mAb (BD Pharmingen, San Diego, $\mathrm{CA}$ ), rabbit anti-IFN- $\gamma$ polyclonal antibody (Abcam, Cambridge, MA) mouse anti-granulysin mAb (Santa Cruz Biotechnology, Dallas, TX), rabbit and mouse anti-CD32A (Abcam, Cambridge, United Kingdom), goat anti-CD56 polyclonal antibody (R\&D Systems, Minneapolis, MN), rabbit anti-CD163 polyclonal antibody (Abcam, Cambridge, United Kingdom), rabbit anti-CD209 (DC-SIGN) polyclonal antibody (Abcam, Cambridge, United Kingdom), rabbit anti-cytokeratin 7 polyclonal antibody (Novus Biologicals, Centennial, CO), mouse anti-cytokeratin 7 mAb (Dako Products, Santa Clara, CA), rabbit anti-vimentin mAb (Abcam, Cambridge, United Kingdom), mouse anti-vimentin IgM mAb (Sigma-Aldrich, St. Louis, MO). Fluorescently labeled secondary antibodies (FITC, Rhodamine RX, and Cy5) were obtained from Jackson Immunoresearch (West Grove, PA).

\section{Immunofluoresence analysis and quantification}

Fluorescent immunostains were imaged using a Leica DMi8 microscope with a Leica DFC9000GT camera controlled by Leica Application Suite X software. Quantification of immune cell types based on marker staining was performed manually using Adobe Photoshop.

\section{Results}

\section{CD56+ cells accumulate at sites of infection in the tissue microenvironment and interact with infected decidual cells}

Antiviral responses often involve the activities of cytotoxic cells, including both NK cells and CD8+ effector memory T (TEM) cells, both of which express CD56 [16]. To determine whether CD56+ immune cells are recruited to sites of infection, we immunostained sections of control and VR1814-infected decidual explants for HCMV IE proteins, CD56, and vimentin, a marker of decidual stromal cells, and examined the spatial relationships between foci of infection and CD56+ cells. We found variable densities of CD56+ cells in control decidua but these were typically distributed randomly (Fig. 1a). In infected decidua explants, in contrast, CD56+ cells accumulated within and 

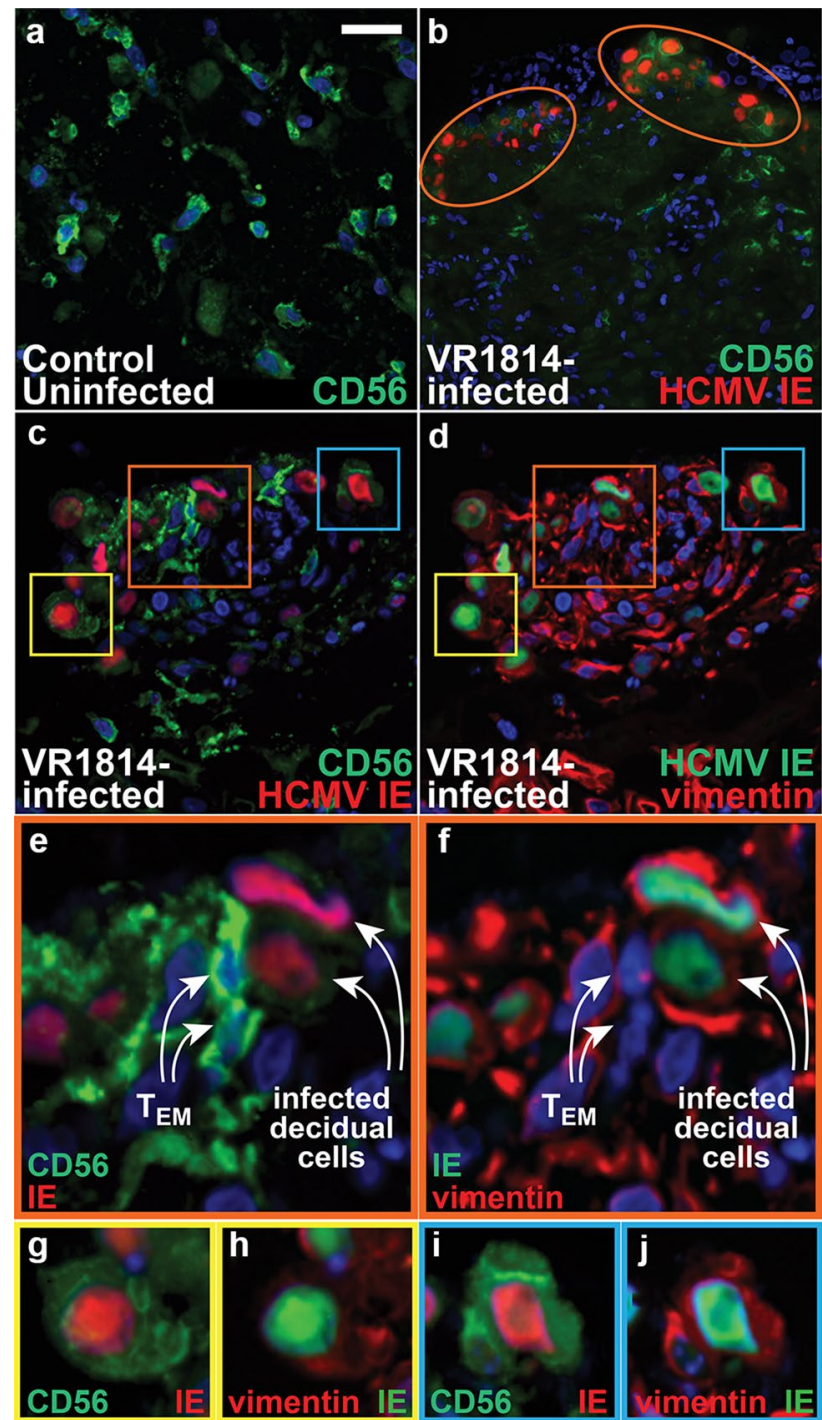

Fig. 1 CD56+ immune cells in basal decidua make direct contact with HCMV-infected cells. Sections of VR1814-infected explants of basal decidua immunostained at 3 days postinfection for CD56, HCMV IE proteins, and vimentin, a marker of decidual stromal cells. a Broad distribution of CD56+ cells in control decidua. b, c CD56+ effector memory CD8+ $\mathrm{T}\left(T_{\mathrm{EM}}\right)$ cells cluster and contact infected decidual cells. d Vimentin costaining of section in C shows HCMV replicates in decidual stromal cells. e, $\mathbf{f}$ Enlargements of areas delineated by orange boxes in $\mathbf{c}$ and $\mathbf{d}$ showing interaction of CD56+ $\mathrm{T}_{\mathrm{EM}}$ cells with infected decidual stromal cells. $\mathbf{g}-\mathbf{j}$ Enlargements of areas delineated by yellow boxes $(\mathbf{g}, \mathbf{h})$ and blue boxes $(\mathbf{I}, \mathbf{j})$ in $\mathbf{c}$ and $\mathbf{d}$ show cells coexpressing CD56, HCMV IE, and vimentin, suggesting that infected cells acquire CD56 by contact with $\mathrm{T}_{\mathrm{EM}}$ cells. Scale bar in $\mathbf{a}=25 \mu \mathrm{m}$ for $\mathbf{a}, \mathbf{c}$ and $\mathbf{d}$, and $50 \mu \mathrm{m}$ for $\mathbf{b}$

near foci of infection (Fig. 1b, c). Immunostaining indicated these cells also expressed CD8 (data not shown), indicating these are CD8+ TEM cells. Vimentin staining confirmed that infected cells were decidual stromal cells; however, unexpectedly, CD56 signal could be seen sideby-side and within some of the infected cells, suggesting
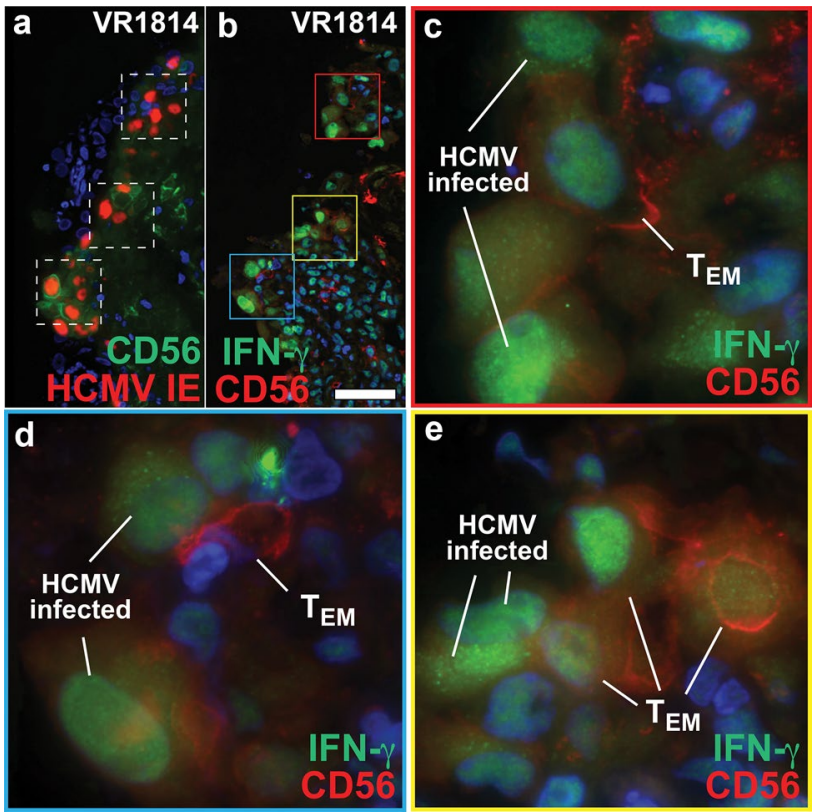

Fig. 2 IFN- $\gamma$ is upregulated at foci of HCMV infection. a, b Parallel sections of decidua infected with VR1814 and stained for CD56 and HCMV IE proteins (a) and CD56 and IFN- $\gamma(\mathbf{b})$ at 3 days postinfection. Dashed boxes surrounding clusters of infected cells in a indicate approximate positions of corresponding colored boxes in $\mathbf{b}$ where IFN- $\gamma$ is upregulated. c-e High magnification images of regions delineated by colored boxes in $\mathbf{b}$. Blue, red, and yellow boxes correspond to panels $\mathbf{c}-\mathbf{e}$, respectively. Scale bar in $\mathbf{b}=50 \mu \mathrm{m}$ for $\mathbf{a}, \mathbf{b}$

uptake from the immune cells. Indeed, CD56+ vimentinnegative cells could be seen interacting with infected decidual cells (orange boxes in Fig. 1c, d and corresponding enlargements in panels e and f). Close examination confirmed that CD56 was densely concentrated in the plasma membranes of infected decidual cells (yellow and blue boxes in Fig. 1c, $d$ and corresponding enlargements in panels $\mathrm{g}-\mathrm{j}$ ).

\section{Interferon- $\gamma$ is upregulated in both immune and decidual cells at sites of infection}

As interferon- $\gamma(\mathrm{IFN}-\gamma)$ is a multifunctional cytokine and central mediator of local immune responses to infections leading to activation of immune cells, we examined IFN- $\gamma$ accumulation at sites of HCMV infection. In parallel sections, clusters of infected decidual cells (Fig. 2a) and clusters of cells with increased levels of IFN- $\gamma$ signal coincided (Fig. 2a, b). Higher magnification images of the areas delineated by colored boxes in panel (b) (Fig. 2c-e, corresponding to the red, blue, and yellow boxes in panel b) reveal intimate relationships between CD8+ TEM cells and infected decidual cells, with both cell types exhibiting increased levels of nuclear IFN- $\gamma$. 


\section{CD8+ TEM cells contact HCMV-infected decidual epithelium}

To examine the relationship of CD56+ immune cells to infection in decidual glands, we immunostained sections of VR1814-infected decidua for CD56 and cytokeratin 19, a marker of epithelial cells. We found that CD56+ cells in VR1814-infected decidua explants infiltrate and traverse the infected epithelium (Fig. 3a). Figure $3 b$ shows an enlargement of the region defined by the yellow box in Fig. 3a, highlighting the intermingling of the CD56+ cells with glandular epithelial cells. Immunostaining of parallel sections for CD3 and CD8 suggest these are CD8+ TEM cells (data not shown). Immunostaining for HCMV IE protein identified three infected epithelial cells in this section, at a site separate from the region of extensive infiltration of CD8+ TEM cells in panel Fig. 3b. Figure 3c shows an enlargement of the region defined by the white box in panel Fig. 3a corresponding to the cluster of infected cells (Fig. 3d), revealing contact between CD8+ TEM cells and infected epithelial cells.
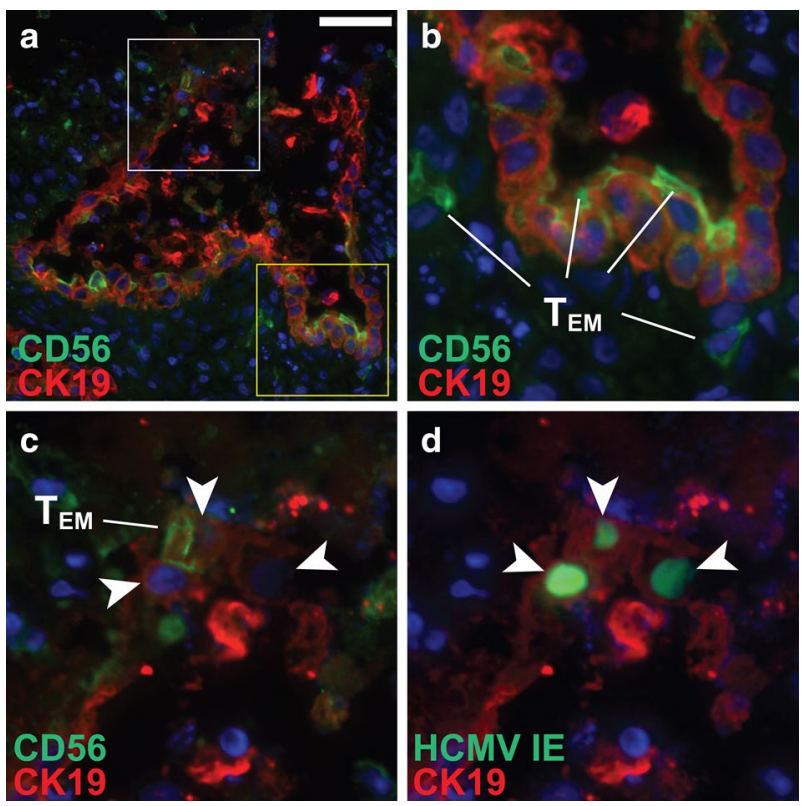

Fig. 3 CD56+ $\mathrm{T}_{\mathrm{EM}}$ cells contact HCMV-infected decidual glands and traffic across the gland epithelium. VR1814-infected decidual explant immunostained for CD56, HCMV IE, and cytokeratin 19 (CK19), a marker of decidual gland epithelium, at 3 days postinfection. a CD56 and CK19 costaining shows CD56+ cells below, within, and above the glandular epithelium. b Enlargement of region delineated by the yellow box in a. c Enlargement of region delineated by the white box in a. d Corresponding HCMV IE signal shows infected epithelial cells (arrowheads) with nearby CD56+ signal. Scale bar in $\mathbf{a}=50 \mu \mathrm{m}$

\section{CD8+ TEM cells express granulysin and those with polarized granules increase in density at sites of infection}

To determine whether CD56+ cells at sites of infection have cytotoxic potential, we immunostained infected decidua for CD56 and granulysin (GNLY), granzyme B, and perforin. Staining for granzyme $\mathrm{B}$ and perforin was negative (data not shown). However, we found that virtually all CD56+ cells near a focus of infection stained strongly for GNLY (Fig. 4a, b), and cells within the focus of infection had a distinctly polar distribution (Fig. 4b, blue and red rectangles, and enlargements in panels $\mathrm{c}$ and $\mathrm{d}$, respectively). In contrast, CD56+ cells more distal to infection frequently exhibited a diffuse granular distribution of GNLY (Fig. 4b, yellow box, and corresponding enlargement in panel e). CD56+ cells in control decidua also expressed GNLY with both polar and diffuse distributions (Fig. 4f and enlargement in Fig. 4g). In some cells, GNLY and CD56 colocalized (Fig. 4d, e). These

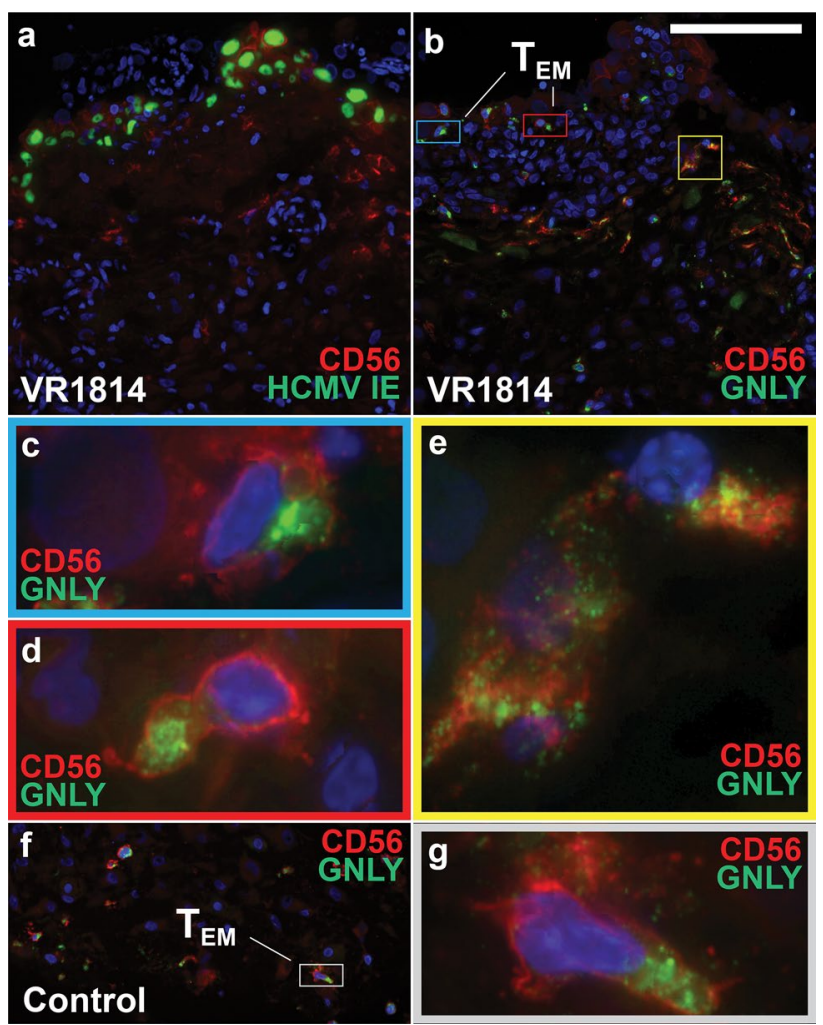

Fig. 4 Granulysin-expressing CD56+ cells proximal to HCMVinfected decidual cells in explants. a, b Parallel sections of VR1814infected decidua immunostained for CD56 and HCMV IE (a) and CD56 and granulysin (GNLY) (b) at 3 days postinfection. c-e High magnification images of regions delineated by the blue and red boxes in $\mathbf{b}$, proximal to the focus of infection $(\mathbf{c}, \mathbf{d})$, and yellow box in $\mathbf{b}$, distal to infection (e). f Section of control decidua immunostained for CD56 and GNLY. g High magnification image of region delineated by box in $\mathbf{f}$. Scale bar in $\mathbf{b}=100 \mu \mathrm{m}$ for $\mathbf{a}, \mathbf{b}$, and $\mathbf{f}$ 
results suggest that the CD8+ TEM cells are attracted to sites of infection and that proximity to infected cells may promote the polar distribution of GNLY in these cells.

\section{Immune cell types in uninfected and HCMV-infected decidual explants and cellular interactions}

To survey immune cell types in decidua explants, we immunostained sections of control and VR1814-infected decidua explants for CD3, CD8, and CD56 and found several

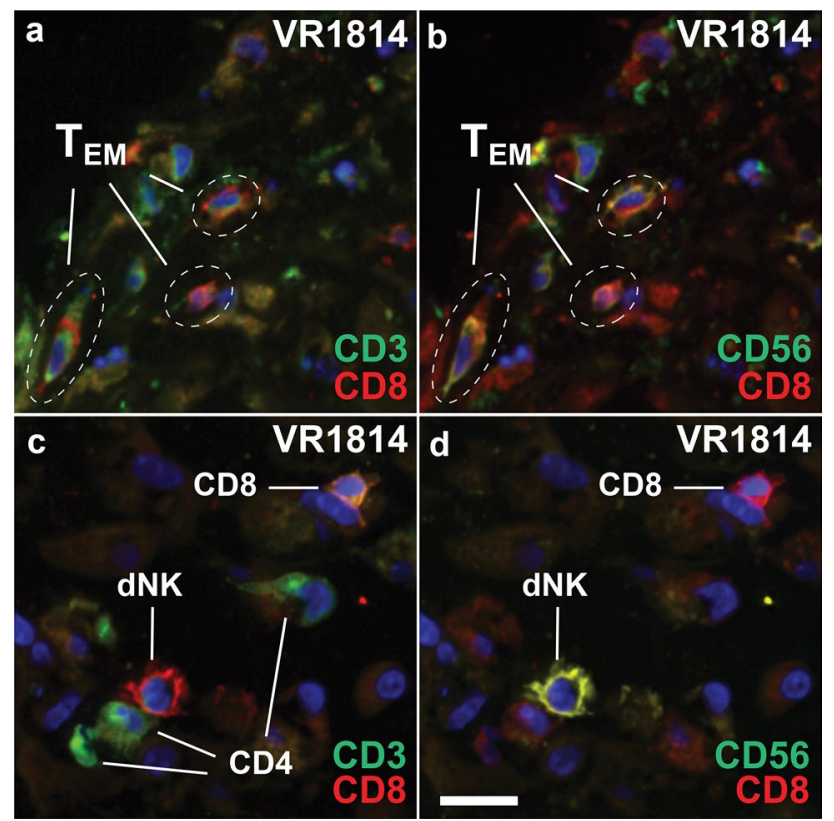

Fig. 5 Immune cell types in HCMV-infected basal decidua. a-d VR1814-infected decidua immunostained for CD3, CD8, and CD56 and separately showing the CD3 and CD8 signals (a, c) and CD56 and CD8 signals $(\mathbf{b}, \mathbf{d})$ at 3 days postinfection. Dashed circles in a and b highlight CD56+ $\mathrm{T}_{\mathrm{EM}}$ cells expressing all three markers. c, $\mathbf{d}$ Show an interaction between CD4+ T cells and a CD8+ decidual NK (dNK) cell. Scale bar in $\mathbf{d}=20 \mu \mathrm{m}$ for $\mathbf{a}-\mathbf{d}$ different cellular phenotypes based on expression of the three markers (Fig. 5). We noted an apparent increase in the relative frequency of CD56+ CD8+ T cells in infected decidua relative to control decidua, later supported by quantification (Table 1). Split images of a single section of infected decidua immunostained for CD3, CD8+ and CD56 reveal TEM cells expressing all three markers (Fig. 5a, b; dashed enclosures). We also observed frequent occurrences of immune cells in pairs, including both homotypic (e.g., two $\mathrm{CD} 8+\mathrm{dNK}$ cells) and heterotypic pairs (e.g., a decidual NK (dNK) cell and a CD8+ T cell). Approximately $20 \%$ of all cells counted were part of a pair. An example is presented in Fig. $5 \mathrm{c}$ and d, where a CD8+ dNK cell is in contact with one of the three CD3 + CD8- CD56- T cells (i.e., likely CD4+ T cells).

\section{Different immune cell frequencies in uninfected and HCMV-infected decidual explants suggest expansion of some cell types upon infection}

To determine whether there were meaningful differences in the frequencies of immune cell types in control and infected decidua explants, we quantified the phenotypes in decidua explants in 14 images of uninfected control and 11 images VR1814-infected decidual explants from two independent basal decidua from seropositive donors fixed at 3 days postinfection and immunostained for CD3, CD8, and CD56 (Table 1). A total of 357 cells expressing at least one of the three markers were counted in control decidua, and a total 374 cells expressing at least one marker were counted in VR1814-infected decidua. The most frequent cell type was dNK (61.6\% in control and $49.7 \%$ in infected explants), some of which expressed CD8 (18.2\% of dNK cells in control and $24.7 \%$ of dNK cells in infected explants). The next most frequent cell type was CD8+ T cell $(29.7 \%$ in control and $33.5 \%$ in infected explants). Notably, there was a large difference between these two CD8+ T cell populations in

Table 1 Immune cell types in basal decidua of first-trimester human placentas

\begin{tabular}{|c|c|c|c|c|c|c|}
\hline \multirow[t]{2}{*}{ Marker } & \multicolumn{6}{|l|}{ Cell type } \\
\hline & $\mathrm{CD} 8+\mathrm{T}$ & $\mathrm{CD} 8+\mathrm{T}_{\mathrm{EM}}$ & dNK & dNK & iNKT & $\mathrm{CD} 4+\mathrm{T}$ \\
\hline CD3 & + & + & - & - & + & + \\
\hline $\mathrm{CD} 8^{\mathrm{a}}$ & + & + & - & + & - & - \\
\hline CD56 & - & + & + & + & + & - \\
\hline CD4 & - & - & - & - & - & + \\
\hline Explant & \multicolumn{6}{|c|}{ Percentage of immune cell total } \\
\hline Control & 28.3 & 1.4 & 50.4 & 11.2 & 4.5 & 2.5 \\
\hline Infected $^{\mathrm{b}}$ & 23.0 & 11.5 & 37.4 & 12.3 & 11.2 & 4.3 \\
\hline
\end{tabular}

${ }^{\mathrm{a}} \mathrm{T}$ cell $\mathrm{CD} 8 \alpha \beta, \mathrm{NK}$ cell CD8 $\alpha \alpha[58]$

${ }^{\mathrm{b}}$ Infected ex vivo with HCMV strain VR1814 
the frequency of CD56 expression, with only $4.7 \%$ of CD8+ $\mathrm{T}$ cells expressing CD56 in control and $34 \%$ of CD8+ T cells expressing CD56 in infected explants, indicating expansion of CD8+ TEM cells in response to HCMV infection. Although fewer in number, there was also a modest increase in the relative frequency of CD56+ CD3 + cells in VR1814-infected decidua relative to control decidua $(4.5 \%$ in control and $11.2 \%$ in infected explants), potentially representing iNKT and/or CD56+ CD4+ T cells. However, immunostaining for CD56 and CD4 reveals few double positives, suggesting most of the CD56+ CD3 + cells are iNKT cells. There was a small increase in the frequency of CD3+ CD8 - CD56-cells in infected relative to control decidua ( $2.5 \%$ in control and $4.3 \%$ in infected explants). Costaining for $\mathrm{CD} 3, \mathrm{CD} 4$, and $\mathrm{CD} 8$ revealed small numbers of CD4+ $\mathrm{T}$ cells and rare CD3+CD4-CD8 $-\gamma \delta \mathrm{T}$ cells (data not shown).

\section{Decidual macrophages/dendritic cells express Fc receptors that could mediate antibody-dependent enhancement of immune responses in HCMV-infected decidua}

To determine whether Fc receptors are present in decidua, we immunostained sections of decidua for the activating IgG receptor Fc $\gamma$ RIIA (CD32A) and the intracellular neonatal Fc receptor FcRn and markers of decidual macrophages and dendritic cells. We found coexpression of FcyRIIA and the macrophage marker CD163 (Fig. 6a) and of FcRn with the dendritic cell/macrophage marker CD209 (Fig. 6b). We also found that most FcyRIIA-expressing cells also expressed FcRn, suggesting that most decidual macrophages and potentially dendritic cells (although few in number) express both Fc $\gamma$ RIIA and FcRn.

\section{Discussion}

In the present study, we used four-color immunofluorescence microscopy to phenotype immune cells in explants of basal decidua from first-trimester human placentas and survey the local cytokine-driven responses to infection ex vivo in the tissue microenvironment. Our analysis found that the clinical HCMV strain VR1814 replicates in decidual cells and epithelial cells of endometrial glands. IFN- $\gamma$ was detected in infected decidual cells and highly differentiated CD8+ TEM cells in contact with them. Both dNK cells and CD8+ TEM produced GNLY, and the latter clustered at sites of infected decidual cells and infiltrated glandular epithelium at distal sites, suggesting chemoattraction. Quantification of immune cells indicated expansion of two subtypes-CD8+ TEM cells and, to a lesser extent, iNKT cells. Approximately $20 \%$ of immune cells were found in pairs, both homotypic and heterotypic, in both control and infected decidua, suggesting frequent cross-talk in the cytokine microenvironment at the uterine-placental interface.

An illustration of the architecture of the uterine-placental interface in first trimester shows a developing chorionic villus and the adjacent basal decidua (Fig. 7, left). Basal decidua is in intimate contact with cytotrophoblasts (CTBs) in the cell columns of anchoring villi of the placenta, thereby providing a means of virus spread from infected decidual cells to placental CTBs and eventually the villus core and fetal blood vessels. HCMV infection has also been confirmed in parietal decidua, in contact with most of the amniochorionic membrane by midgestation (Fig. 7, right). Although less well studied, the parietal decidua may also mediate virus transmission to the fetal compartment via the amniochorionic membrane, as suggested for Zika virus infection [17]. dNK cells, macrophages, and other immune cells present in human decidua, and HCMV-reactive CD8+ TEM cells in seropositive women, permit invasion of the basal decidua by the hemiallogeneic CTBs. Nonetheless, exposure to HCMV in early pregnancy leads to increased production of IFN- $\gamma$ and potentially a variety of cellular responses, including activation and proliferation of immune cells already present and additional recruitment of virusspecific immune cells from circulation [18-20].

In support of this possibility, HCMV-seropositive women have increased levels of circulating CD8+ TEM cells that could protect against virus transmission [21, 22]. A large percentage of $\mathrm{CD} 8+\mathrm{T}$ cells isolated from decidua are
Fig. 6 Decidual macrophages and dendritic cells express the cell surface $\mathrm{Fc}$ receptor Fc $\gamma$ RIIA and the intracellular neonatal Fc receptor FcRn. Basal decidua infected with VR1814 and immunostained for CD163 and Fc $\gamma$ RIIA (a), CD209 and FcRn (b), and both FcyRIIA and FcRn (c) at 3 days postinfection. Scale bar in a $=20 \mu \mathrm{m}$ for $\mathbf{a}-\mathbf{c}$
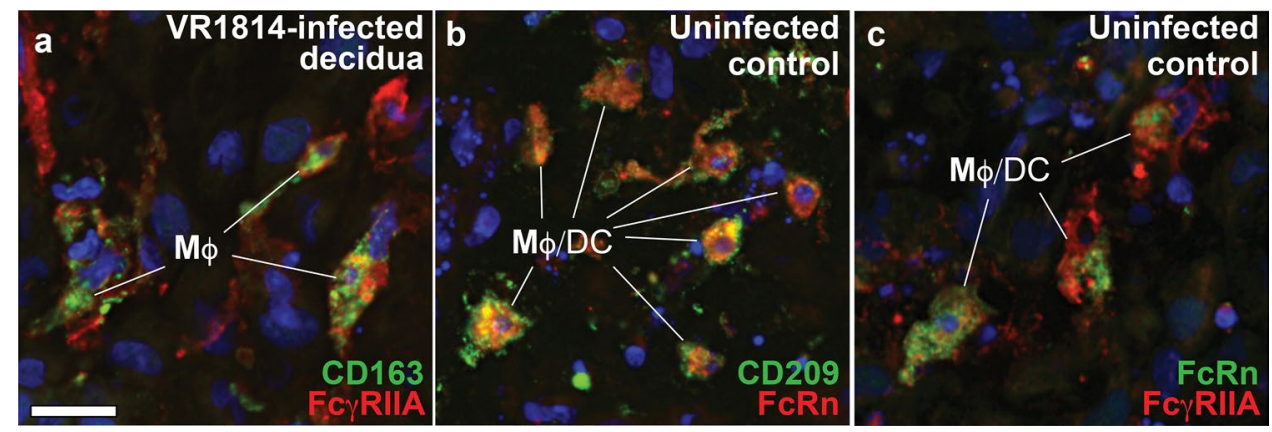


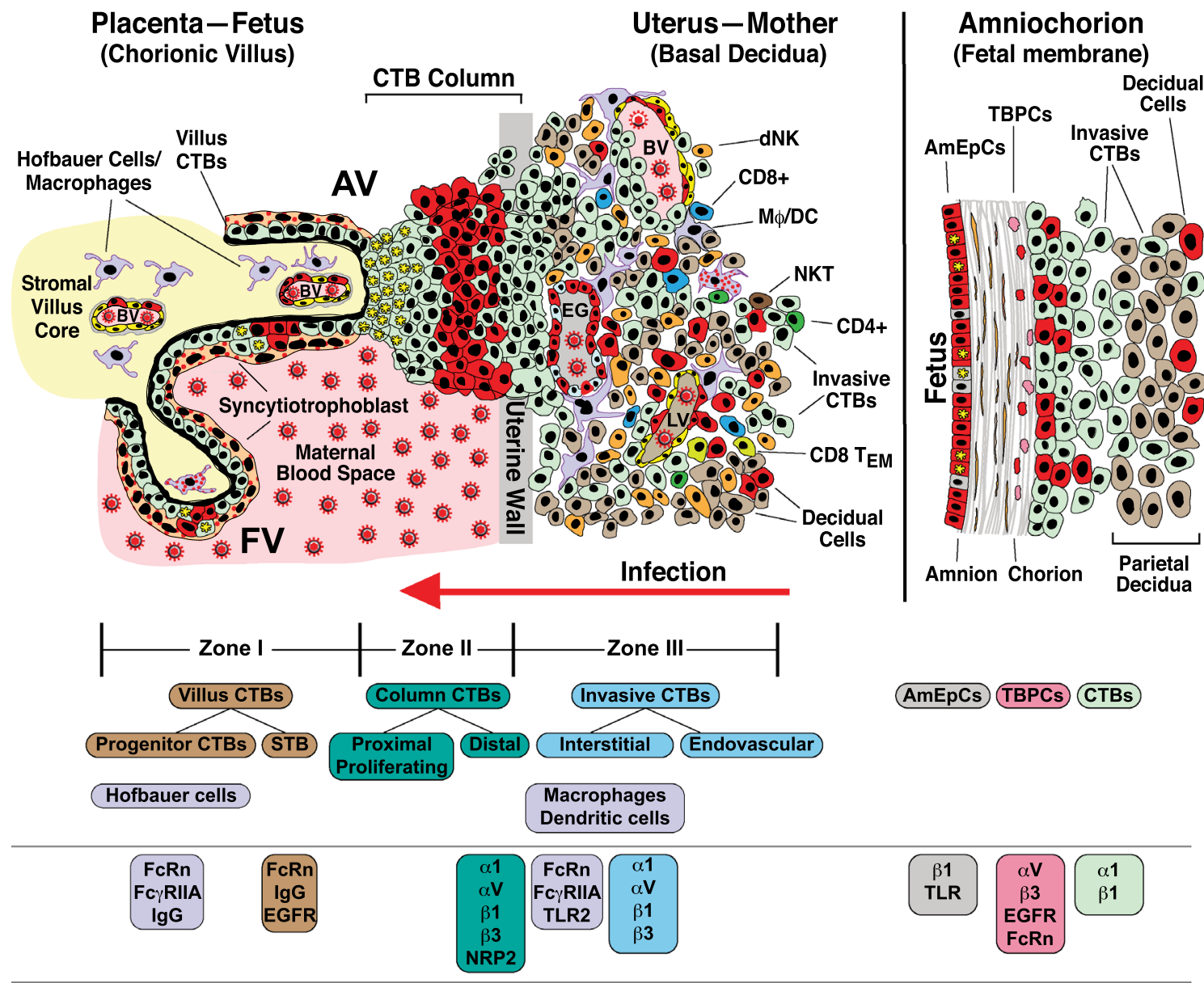

Fig. 7 HCMV infection and repertoire of immune cells at the uterine-placental interface. Diagram of two zones of uterine-placental interface depicting HCMV infection (red cytoplasm) in explants of first-trimester chorionic villi and basal decidua and biopsy specimens from term placentas (modified from [57]). Left: the placental interface with basal decidua. Red arrow indicates direction of transmission of infection. In chorionic villus explants, HCMV replicates in cytotrophoblasts (CTBs) in cell columns (Zone II). In decidual explants, HCMV replicates in decidual stromal cells, epithelial cells of endometrial glands (EG), and macrophages/dendritic cells (Mф/ DCs; Zone III). Other immune cells include decidual natural killer
(dNK) cells, CD8+ T cells, CD8+ CD56+ effector memory T cells $\left(\mathrm{CD} 8+\mathrm{T}_{\mathrm{EM}}\right), \mathrm{CD} 56+\mathrm{CD} 3+$ natural killer T (NKT) cells, and CD4+ $\mathrm{T}$ cells. Right: the amniochorionic membrane interface with parietal decidua, which forms by mid-gestation with the growth of the fetus and enlargement of the amniotic sac. At delivery, HCMV infection is found in amniotic epithelial cells of the amniochorionic membrane surrounding the fetus, as well as trophoblast progenitor cells of the chorion and the CTB layer interposed between membrane and parietal decidual cells. Below: cell surface molecules that function as HCMV receptors/co-receptors and function in the immune responses to infection effector memory, suggesting recruitment from the circulating pool $[23,24]$. Accordingly, the cellular immune response may include proliferation of TEM cells, consistent with our finding of increased frequencies of CD8+ TEM cells in VR1814-infected versus control decidual explants at 3 days postinfection.

Human pregnancy presents an immunological challenge-simultaneously allowing development of the allogeneic fetus and placenta and the capability to control disseminated viral infections. Recent studies described lymphoproliferative responses after primary HCMV infection in mothers who transmit virus compared to those who do not [25]. During the first month after seroconversion, expansion of IFN- $\boldsymbol{\gamma}$-producing HCMV-specific CD4 + and $\mathrm{CD} 8+\mathrm{T}$ cells correlated with virus clearance from blood. Delayed expansion of these cells was observed in infected mothers who transmitted virus as compared with those who did not, suggesting the $\mathrm{T}$ cell immune response influences vertical transmission. Further analysis found that HCMVspecific CD45RA+ CD4+ and CD8+ TEM cells increased up to 3 months after primary infection, with significantly high levels maintained in mothers who did not transmit infection [14], and TEM IL-7R-negative cells were maintained in seropositive women long after primary infection [22]. HCMV serostatus has a profound effect on maternal immune cell phenotype and cytokine profile in healthy 
pregnant women by modulating changes in CD8+ T cells during gestation [21]. Naive CD8+ T cells that were CCR7+ CD45RA+ were reduced significantly in HCMV-seropositive women, whereas the proportion of $\mathrm{CD} 8+\mathrm{T}$ cells that were CCR7 - CD45RA+ increased, demonstrating an accumulation of highly differentiated $\mathrm{HCMV}$-specific T cells in circulation in the course of pregnancy.

Our preliminary results suggest that context-dependent cytokine signaling influences immune cells in the microenvironment of human decidua and that inflammatory cytokines could activate antiviral responses in utero. We found that the density of decidual CD8+ TEM cells increases around foci of infection, possibly driven by IFN- $\gamma$, and these cells produce GNLY, suggesting they engage in antiviral activities. It was recently shown that cytotoxic $\mathrm{T}$ cells target intracellular pathogens using a combination of perforin, GNLY, and granzyme B [26]. Despite mixed signals of tolerance and immunity and low levels of perforin and granzyme B, highly differentiated CD8+ TEM cells isolated from decidua degranulate upon in vitro stimulation [23, 27]. GNLY also functions as a chemoattractant at a range of concentrations that increase the chemotaxis of CD8+ TEM and dNK cells [28]. IFN- $\gamma$ has multiple functions, suggesting it could also increase the abundance of CD8+ TEM cells by local proliferation [29]. Moreover, IFN- $\gamma$ is a dominant paracrine trigger that skews CD8+ T cell differentiation by contactdependent $\mathrm{T}$ cell-T cell interactions and localized IFN- $\gamma$ secretion among activated cells [30]. Following bacterial infection, IFN- $\gamma$ costimulation by integrins at cell-cell synapses modulates CD8+ T cell differentiation and shows how cell clusters and the microenvironment drive unique biology. Another striking feature of the cell-cell interactions we observed was the density of CD56 in the plasma membranes of TEM cells at sites of contact with infected decidual cells expressing HCMV IE proteins (Figs. 1, 2, 3, 4). Although CD56 (neural cell adhesion molecule, NCAM) is considered a marker of NK cells, it is expressed by many more immune cell types with strong immunostimulatory effector functions and efficient cytotoxic capacity [16,31]. It is possible that TEM cells use CD56 to engage infected decidual cells via the fibroblast growth factor receptor to deliver signals and modulate cytokine production [32-35].

Moderate expansion of iNKT cells was also observed in HCMV-infected decidua. iNKT cells have diverse immune stimulatory and regulatory activities through their ability to release cytokines and to kill or transactivate target cells [36]. In mice, iNKT cells produce IFN- $\gamma$ that stimulates NK and CD8+ T cells to eliminate influenza virus $[37,38]$. It remains to be determined whether specific cytokines drive iNKT cell expansion in infected decidua as reported for murine CMV-infected mice [39].

Vaccines to HCMV are under development, but the optimal targets of neutralization have not yet been defined, and antiviral functions attributed to neutralizing antibodies are poorly understood, as shown by a subunit $\mathrm{gB}$ vaccine that proved only partially protective [40-42]. Of importance to development of humoral immune responses to HCMV, we found macrophages and dendritic cells in basal decidua express FcyRIIA and FcRn that cooperate during binding and degradation of immune complexes for antigen presentation and activation of T cells [43-45]. In this regard, studies of women who seroconverted during early pregnancy and were treated with hyperimmune globulin [46-48] showed protection against severe outcomes, but the results varied [49]. In fact, the mechanisms by which HCMV-specific antibodies influence transmission have not been determined, nor have the protective antibodies to specific glycoproteins been clearly defined. Our results suggest that HCMV-specific IgG could also have effects on immune cells bearing FcRs in basal decidua [50, 43] and might activate "memory-like" dNK cells, leading to proliferation and antiviral effects at local sites of infection $[51,52]$. It is possible that monoclonal antibodies with defined properties that bind FcRs could mimic these protective effects and greatly improve upon them as the critical mechanisms of protection are uncovered.

In conclusion, in situ analysis of immune cells in basal decidua has allowed us to document spatial relationships, including the highly localized upregulation of IFN- $\gamma$ at foci of infection, the frequent occurrence of both homotypic and heterotypic cell pairs, suggesting extensive cross-talk among immune cells in the natural environment, and the extraordinary comingling of CD56+ cells with glandular epithelia, suggestive of aggressive surveillance of epithelial barriers at a site HCMV frequently targets during pregnancy. Analysis of isolated immune cells from maternal circulation [21] and basal and parietal decidua provides a collective picture of phenotypes and shows activation in vitro by HCMV infection [23, 27], indicative of dynamic interactions between virus and $\mathrm{T}$ cells. Nonetheless, the battle against transmission occurs at foci of infection in the microenvironment and is dependent at early stages on cells that have already been recruited to and continue to be maintained in basal decidua. More detailed analysis of the phenotypes of immune cells, their specific relationships to other cells and sites of infection, cytokine production, etc., may therefore reveal the complexity of interactions and specific responses not easily studied or anticipated by studies on isolated cells or peripheral blood cells. This is particularly true for cell types that are less abundant but could play a critical role in the overall response to focal HCMV infection. For example, remodeling of lipids in vesicles associated with viral assembly and egress [53] could activate iNKT cells that recognize endogenous lipids in the context of CD1d molecules and lead to enhanced priming of antigen-specific T cell responses [36, 54]. Whether CD8+ TEM cells that target foci of HCMV infection in basal decidua have the 
phenotype of resident $\mathrm{CD} 8+\mathrm{T}$ cells that are recruited from circulation to sites of persistent infection is unknown [55]. In this regard, the presence of CD8+ TEM and HCMV-specific neutralizing antibodies is advantageous to reduce the viral load and prevent transmission but could also lead to immune senescence in multiparous women. Recently, a detailed analysis of maternal and fetal cells in early pregnancy at the single-cell level generated a repository of ligand-receptor complexes that predict the cell-type specificity of cell-cell communication via these molecular interactions [56]. Many regulatory interactions that prevent harmful innate or adaptive immune responses in this microenvironment were identified and include the interactions critical for reproductive success. Cross-talk between immune cells and their targets that occurs as HCMV replicates in the microenvironment at the uterine-placental interface remains to be fully elucidated.

Acknowledgements This work was supported by the National Institutes of Health Institute of Allergy and Infectious Diseases Grants RO1AI046657, R56AI101130, and R21AI129508 (L.P.), the Eunice Kennedy Shriver National Institute of Child Health and Human Development Grant R21HD061890 (T.T.), the University of California, San Francisco California Preterm Birth Initiative grant (T.T.).

\section{Compliance with ethical standards}

Conflict of interest The authors declare they have no conflict of interest.

Ethical approval All work with human tissue was performed with the approval of the Institutional Review Board of the University of California, San Francisco.

\section{References}

1. Pass RF, Fowler KB, Boppana SB, Britt WJ, Stagno S (2006) Congenital cytomegalovirus infection following first trimester maternal infection: symptoms at birth and outcome. J Clin Virol 35:216-220

2. Enders G, Daiminger A, Bader U, Exler S, Enders M (2011) Intrauterine transmission and clinical outcome of 248 pregnancies with primary cytomegalovirus infection in relation to gestational age. J Clin Virol 52:244-246

3. Picone O, Vauloup-Fellous C, Cordier AG, Guitton S, Senat MV, Fuchs F, Ayoubi JM, Grangeot Keros L, Benachi A (2013) A series of 238 cytomegalovirus primary infections during pregnancy: description and outcome. Prenat Diagn 33:751-758

4. Faure-Bardon V, Magny JF, Parodi M, Couderc S, Garcia P, Maillotte AM, Benard M, Pinquier D, Astruc D, Patural H, Pladys P, Parat S, Guillois B, Garenne A, Bussieres L, Guilleminot T, Stirnemann J, Ghout I, Ville Y, Leruez-Ville M (2018) Sequelae of congenital cytomegalovirus (cCMV) following maternal primary infection are limited to those acquired in the first trimester of pregnancy. Clin Infect Dis. https://doi.org/10.1093/cid/ciy1128

5. Pereira L, Maidji E, McDonagh S, Genbacev O, Fisher S (2003) Human cytomegalovirus transmission from the uterus to the placenta correlates with the presence of pathogenic bacteria and maternal immunity. J Virol 77:13301-13314
6. Weisblum Y, Panet A, Zakay-Rones Z, Haimov-Kochman R, Goldman-Wohl D, Ariel I, Falk H, Natanson-Yaron S, Goldberg MD, Gilad R, Lurain NS, Greenfield C, Yagel S, Wolf DG (2011) Modeling of human cytomegalovirus maternal-fetal transmission in a novel decidual organ culture. J Virol 85:13204-13213

7. Pereira L, Petitt M, Fong A, Tsuge M, Tabata T, Fang-Hoover J, Maidji E, Zydek M, Zhou Y, Inoue N, Loghavi S, Pepkowitz S, Kauvar LM, Ogunyemi D (2014) Intrauterine growth restriction caused by underlying congenital cytomegalovirus infection. J Infect Dis 209:1573-1584

8. McDonagh S, Maidji E, Ma W, Chang HT, Fisher S, Pereira L (2004) Viral and bacterial pathogens at the maternal-fetal interface. J Infect Dis 190:826-834

9. McDonagh S, Maidji E, Chang HT, Pereira L (2006) Patterns of human cytomegalovirus infection in term placentas: a preliminary analysis. J Clin Virol 35:210-215

10. Nozawa N, Fang-Hoover J, Tabata T, Maidji E, Pereira L (2009) Cytomegalovirus-specific, high-avidity IgG with neutralizing activity in maternal circulation enriched in the fetal bloodstream. J Clin Virol 46(Suppl 4):S58-63

11. Tabata T, Petitt M, Fang-Hoover J, Zydek M, Pereira L (2016) Persistent cytomegalovirus infection in amniotic membranes of the human placenta. Am J Pathol 186:2970-2986

12. Tabata T, Petitt M, Puerta-Guardo H, Michlmayr D, Harris E, Pereira L (2018) Zika virus replicates in proliferating cells in explants from first-trimester human placentas, potential sites for dissemination of infection. J Infect Dis 217:1202-1213

13. Weisblum Y, Oiknine-Djian E, Vorontsov OM, Haimov-Kochman R, Zakay-Rones Z, Meir K, Shveiky D, Elgavish S, Nevo Y, Roseman M, Bronstein M, Stockheim D, From I, Eisenberg I, Lewkowicz AA, Yagel S, Panet A, Wolf DG (2017) Zika virus infects early- and midgestation human maternal decidual tissues, inducing distinct innate tissue responses in the maternal-fetal interface. J Virol 91:e01905-01916

14. Fornara C, Furione M, Arossa A, Gerna G, Lilleri D (2016) Comparative magnitude and kinetics of human cytomegalovirus-specific CD4+(+) and CD8+(+) T-cell responses in pregnant women with primary versus remote infection and in transmitting versus non-transmitting mothers: its utility for dating primary infection in pregnancy. J Med Virol 88:1238-1246

15. Lilleri D, Kabanova A, Revello MG, Percivalle E, Sarasini A, Genini E, Sallusto F, Lanzavecchia A, Corti D, Gerna G (2013) Fetal human cytomegalovirus transmission correlates with delayed maternal antibodies to gH/gL/pUL128-130-131 complex during primary infection. PLoS One 8:e59863

16. Van Acker HH, Capsomidis A, Smits EL, Van Tendeloo VF (2017) CD56 in the immune system: more than a marker for cytotoxicity? Front Immunol 8:892. https://doi.org/10.3389/fimmu .2017 .00892

17. Tabata T, Petitt M, Puerta-Guardo H, Michlmayr D, Wang C, Fang-Hoover J, Harris E, Pereira L (2016) Zika virus targets different primary human placental cells, suggesting two routes for vertical transmission. Cell Host Microbe 20:155-166

18. Co EC, Gormley M, Kapidzic M, Rosen DB, Scott MA, Stolp HA, McMaster M, Lanier LL, Barcena A, Fisher SJ (2013) Maternal decidual macrophages inhibit NK cell killing of invasive cytotrophoblasts during human pregnancy. Biol Reprod 88:155. https ://doi.org/10.1095/biolreprod.112.099465

19. van den Heuvel M, Peralta C, Bashar S, Taylor S, Horrocks J, Croy BA (2005) Trafficking of peripheral blood CD56(bright) cells to the decidualizing uterus-new tricks for old dogmas? J Reprod Immunol 67:21-34

20. Chantakru S, Miller C, Roach LE, Kuziel WA, Maeda N, Wang WC, Evans SS, Croy BA (2002) Contributions from self-renewal and trafficking to the uterine NK cell population of early pregnancy. J Immunol 168:22-28 
21. Lissauer D, Choudhary M, Pachnio A, Goodyear O, Moss PA, Kilby MD (2011) Cytomegalovirus sero positivity dramatically alters the maternal $\mathrm{CD} 8++\mathrm{T}$ cell repertoire and leads to the accumulation of highly differentiated memory cells during human pregnancy. Hum Reprod 26:3355-3365

22. Mele F, Fornara C, Jarrossay D, Furione M, Arossa A, Spinillo A, Lanzavecchia A, Gerna G, Sallusto F, Lilleri D (2017) Phenotype and specificity of $\mathrm{T}$ cells in primary human cytomegalovirus infection during pregnancy: IL-7Rpos long-term memory phenotype is associated with protection from vertical transmission. PLoS One 12:e0187731

23. Tilburgs T, Schonkeren D, Eikmans M, Nagtzaam NM, Datema G, Swings GM, Prins F, van Lith JM, van der Mast BJ, Roelen DL, Scherjon SA, Claas FH (2010) Human decidual tissue contains differentiated CD8++ effector-memory T cells with unique properties. J Immunol 185:4470-4477

24. Tilburgs T, Strominger JL (2013) CD8++ effector T cells at the fetal-maternal interface, balancing fetal tolerance and antiviral immunity. Am J Reprod Immunol 69:395-407

25. Lilleri D, Fornara C, Furione M, Zavattoni M, Revello MG, Gerna G (2007) Development of human cytomegalovirus-specific T cell immunity during primary infection of pregnant women and its correlation with virus transmission to the fetus. J Infect Dis 195:1062-1070

26. Dotiwala F, Mulik S, Polidoro RB, Ansara JA, Burleigh BA, Walch M, Gazzinelli RT, Lieberman J (2016) Killer lymphocytes use granulysin, perforin and granzymes to kill intracellular parasites. Nat Med 22:210-216

27. van der Zwan A, Bi K, Norwitz ER, Crespo AC, Claas FHJ, Strominger JL, Tilburgs T (2018) Mixed signature of activation and dysfunction allows human decidual CD8+(+) T cells to provide both tolerance and immunity. Proc Natl Acad Sci USA 115:385-390

28. Deng A, Chen S, Li Q, Lyu SC, Clayberger C, Krensky AM (2005) Granulysin, a cytolytic molecule, is also a chemoattractant and proinflammatory activator. J Immunol 174:5243-5248

29. Whitmire JK, Tan JT, Whitton JL (2005) Interferon-gamma acts directly on $\mathrm{CD} 8++\mathrm{T}$ cells to increase their abundance during virus infection. J Exp Med 201:1053-1059

30. Krummel MF, Mahale JN, Uhl LFK, Hardison EA, Mujal AM, Mazet JM, Weber RJ, Gartner ZJ, Gerard A (2018) Paracrine costimulation of IFN-gamma signaling by integrins modulates CD8+ T cell differentiation. Proc Natl Acad Sci U S A 115:11585-11590

31. Albayati Z, Alyami A, Alomar S, Middleton D, Bonnett L, Aleem S, Flanagan BF, Christmas SE (2017) The influence of cytomegalovirus on expression of HLA-G and its ligand KIR2DL4 by human peripheral blood leucocyte subsets. Scand J Immunol 86:396-407

32. Kos FJ, Engleman EG (1995) Requirement for natural killer cells in the induction of cytotoxic T cells. J Immunol 155:578-584

33. Kos FJ, Chin CS (2002) Costimulation of T cell receptor-triggered IL-2 production by Jurkat T cells via fibroblast growth factor receptor 1 upon its engagement by CD56. Immunol Cell Biol 80:364-369

34. Sorensen V, Zhen Y, Zakrzewska M, Haugsten EM, Walchli S, Nilsen T, Olsnes S, Wiedlocha A (2008) Phosphorylation of fibroblast growth factor (FGF) receptor 1 at Ser777 by p38 mitogenactivated protein kinase regulates translocation of exogenous FGF1 to the cytosol and nucleus. Mol Cell Biol 28:4129-4141

35. Ahmed Z, Schuller AC, Suhling K, Tregidgo C, Ladbury JE (2008) Extracellular point mutations in FGFR2 elicit unexpected changes in intracellular signalling. Biochem J 413:37-49

36. Schonrich G, Raftery MJ (2018) CD1-restricted T cells during persistent virus infections: "Sympathy for the Devil". Front Immunol 9:545. https://doi.org/10.3389/fimmu.2018.00545
37. O'Reilly V, Zeng SG, Bricard G, Atzberger A, Hogan AE, Jackson J, Feighery C, Porcelli SA, Doherty DG (2011) Distinct and overlapping effector functions of expanded human CD4++, CD8+ alpha+ and CD4+-CD8+alpha-invariant natural killer T cells. PLoS One 6:e28648

38. Ishikawa H, Tanaka K, Kutsukake E, Fukui T, Sasaki H, Hata A, Noda S, Matsumoto T (2010) IFN-gamma production downstream of NKT cell activation in mice infected with influenza virus enhances the cytolytic activities of both NK cells and viral antigen-specific CD8++ T cells. Virology 407:325-332

39. Tyznik AJ, Verma S, Wang Q, Kronenberg M, Benedict CA (2014) Distinct requirements for activation of NKT and NK cells during viral infection. J Immunol 192:3676-3685

40. Pass RF, Zhang C, Evans A, Simpson T, Andrews W, Huang ML, Corey L, Hill J, Davis E, Flanigan C, Cloud G (2009) Vaccine prevention of maternal cytomegalovirus infection. $\mathrm{N}$ Engl J Med 360:1191-1199

41. Baraniak I, Kropff B, Ambrose L, McIntosh M, McLean GR, Pichon S, Atkinson C, Milne RSB, Mach M, Griffiths PD, Reeves MB (2018) Protection from cytomegalovirus viremia following glycoprotein B vaccination is not dependent on neutralizing antibodies. Proc Natl Acad Sci USA 115:6273-6278

42. Baraniak I, Kropff B, McLean GR, Pichon S, Piras-Douce F, Milne RSB, Smith C, Mach M, Griffiths PD, Reeves MB (2018) Epitope-specific humoral responses to human cytomegalovirus glycoprotein-B vaccine with MF59: anti-AD2 levels correlate with protection from viremia. J Infect Dis 217:1907-1917

43. Baker K, Rath T, Lencer WI, Fiebiger E, Blumberg RS (2013) Cross-presentation of IgG-containing immune complexes. Cell Mol Life Sci 70:1319-1334

44. Rath T, Kuo TT, Baker K, Qiao SW, Kobayashi K, Yoshida M, Roopenian D, Fiebiger E, Lencer WI, Blumberg RS (2013) The immunologic functions of the neonatal Fc receptor for IgG. J Clin Immunol 33(Suppl 1):S9-17

45. Baker K, Qiao SW, Kuo TT, Aveson VG, Platzer B, Andersen JT, Sandlie I, Chen Z, de Haar C, Lencer WI, Fiebiger E, Blumberg RS (2011) Neonatal Fc receptor for IgG (FcRn) regulates cross-presentation of $\mathrm{IgG}$ immune complexes by CD8+-CD11b+ dendritic cells. Proc Natl Acad Sci USA 108:9927-9932

46. Kagan KO, Enders M, Schampera MS, Baeumel E, Hoopmann M, Geipel A, Berg C, Goelz R, De Catte L, Wallwiener D, Brucker S, Adler SP, Jahn G, Hamprecht K (2018) Prevention of maternal-fetal transmission of CMV by hyperimmunoglobulin (HIG) administered after a primary maternal CMV infectionin early gestation. Ultrasound Obstet Gynecol. https://doi.org/10.1002/ uog. 19164

47. Buxmann H, Stackelberg OM, Schlosser RL, Enders G, Gonser M, Meyer-Wittkopf M, Hamprecht K, Enders M (2012) Use of cytomegalovirus hyperimmunoglobulin for prevention of congenital cytomegalovirus disease: a retrospective analysis. J Perinat Med 40:439-446

48. Nigro G, Adler SP, La Torre R, Best AM (2005) Passive immunization during pregnancy for congenital cytomegalovirus infection. N Engl J Med 353:1350-1362

49. Revello MG, Lazzarotto T, Guerra B, Spinillo A, Ferrazzi E, Kustermann A, Guaschino S, Vergani P, Todros T, Frusca T, Arossa A, Furione M, Rognoni V, Rizzo N, Gabrielli L, Klersy C, Gerna G, Group CS (2014) A randomized trial of hyperimmune globulin to prevent congenital cytomegalovirus. N Engl J Med 370:1316-1326

50. Qiao SW, Kobayashi K, Johansen FE, Sollid LM, Andersen JT, Milford E, Roopenian DC, Lencer WI, Blumberg RS (2008) Dependence of antibody-mediated presentation of antigen on FcRn. Proc Natl Acad Sci USA 105:9337-9342 
51. Lee J, Zhang T, Hwang I, Kim A, Nitschke L, Kim M, Scott JM, Kamimura Y, Lanier LL, Kim S (2015) Epigenetic modification and antibody-dependent expansion of memory-like NK cells in human cytomegalovirus-infected individuals. Immunity 42:431-442

52. Sun JC, Beilke JN, Lanier LL (2010) Immune memory redefined: characterizing the longevity of natural killer cells. Immunol Rev 236:83-94

53. Liu ST, Sharon-Friling R, Ivanova P, Milne SB, Myers DS, Rabinowitz JD, Brown HA, Shenk T (2011) Synaptic vesiclelike lipidome of human cytomegalovirus virions reveals a role for SNARE machinery in virion egress. Proc Natl Acad Sci USA 108:12869-12874

54. McEwen-Smith RM, Salio M, Cerundolo V (2015) CD1d-dependent endogenous and exogenous lipid antigen presentation. Curr Opin Immunol 34:116-125

55. Gordon CL, Miron M, Thome JJ, Matsuoka N, Weiner J, Rak MA, Igarashi S, Granot T, Lerner H, Goodrum F, Farber DL (2017) Tissue reservoirs of antiviral $\mathrm{T}$ cell immunity in persistent human CMV infection. J Exp Med 214:651-667
56. Vento-Tormo R, Efremova M, Botting RA, Turco MY, VentoTormo M, Meyer KB, Park JE, Stephenson E, Polanski K, Goncalves A, Gardner L, Holmqvist S, Henriksson J, Zou A, Sharkey AM, Millar B, Innes B, Wood L, Wilbrey-Clark A, Payne RP, Ivarsson MA, Lisgo S, Filby A, Rowitch DH, Bulmer JN, Wright GJ, Stubbington MJT, Haniffa M, Moffett A, Teichmann SA (2018) Single-cell reconstruction of the early maternal-fetal interface in humans. Nature 563:347-353

57. Pereira L (2018) Congenital viral infection: traversing the uterine-placental interface. Annu Rev Virol. https://doi.org/10.1146/ annurev-virology-092917-043236

58. Gao GF, Willcox BE, Wyer JR, Boulter JM, O'Callaghan CA, Maenaka K, Stuart DI, Jones EY, Van Der Merwe PA, Bell JI, Jakobsen BK (2000) Classical and nonclassical class I major histocompatibility complex molecules exhibit subtle conformational differences that affect binding to CD8+alphaalpha. J Biol Chem 275:15232-15238

Publisher's Note Springer Nature remains neutral with regard to jurisdictional claims in published maps and institutional affiliations. 